\title{
OBITUARY
}

\section{WILLIAM STUART-LOW}

William Stuart-Low's death from heart failure following influenza was the end of a very remarkable career. $\mathrm{He}$ was born at Burntisland, in Fife, in 1857 . His father was in the scholastic profession and doubtless bequeathed to him the capacity for teaching which displayed itself when he joined the staff of the Central London Throat and Ear Hospital. At the Polyclinic also he made his mark as a teacher and thereby added considerably to his success in consulting practice. It is interesting to recall that his class of Rhinology was one of the best attended and financially one of the most profitable in the institution. While in busy practice he made time for preparing for the Fellowship of the Royal College of Surgeons of England and was particularly inspired by the teaching of the late William Anderson, Surgeon to St. Thomas's Hospital, for whose anatomical accuracy and surgical refinement he had the greatest admiration. He had some original views which, when tested in his own practice, had a measure of success, even when they were not shared by his colleagues. His insistence on the value of mucin in cancer of the throat was the result of deductions which he elaborated in his work on Mucous Membranes, Normal and Abnormal, including Mucin and Malignancy. He insisted that malignant disease selected in particular those regions which were least provided with mucous glands and that the occurrence of cancer was favoured by hypomyxia. This in its turn was induced by excessive tobacco-smoking and consumption of salt. Whether the logic of his reasoning is acceptable or not, the preparations of mucin which he devised seemed to give relief in many cases of malignant disease in the region of the throat.

James Dundas-Grant. 